\title{
Citizen science in cities: an overview of projects focused on urban Australia
}

\author{
Erin $\operatorname{Roger}^{1}$ (D) Alice Motion ${ }^{2,3}$ (D)
}

Accepted: 10 November 2021 / Published online: 18 November 2021

(c) Crown 2021

\begin{abstract}
Citizen science offers a unique opportunity to connect urban-dwellers with the often hidden natural world upon their doorsteps and to contribute to authentic research that increases knowledge of urban ecology and biodiversity. With the majority of Australia's population residing in large cities, this diverse potential pool of participants in science creates a significant opportunity to increase the spatial and temporal scale of research. Herein, we provide an overview of Australian urban citizen science projects based on an analysis of the projects listed in the Australian Citizen Science Association's Citizen Science Project Finder. We draw out key features (such as those with research questions specific to cities such as reintroduction and persistence of species in urban environments) from urban citizen science projects that make them suitable for the urban environment and use these features to suggest recommendations for further expansion and development of this important subset of projects. We conclude that the number and diversity of urban citizen science projects is relatively low in Australia, and advocate for an increase in initiatives that can tap into a large pool of potential participants for the benefit of science and society.
\end{abstract}

Keywords Citizen science $\cdot$ Ecology $\cdot$ Urban $\cdot$ Cities $\cdot$ Biodiversity $\cdot$ Australia

\section{Introduction}

Globally, citizen science has experienced unprecedented growth over the past decade, largely due to advances in, and availability of, technology which has facilitated the involvement of millions of people in science (Bonney et al. 2014; Roger et al. 2019). Citizen science can include (but is not limited to) a broad range of activities, from analysing scientific data, sharing health information, mapping galaxies and making new low-cost technologies (Bonney et al. 2014; Chandler et al. 2017; Roger et al. 2020). Citizen science can also deliver a level of spatial and temporal granularity often not possible with conventional scientific research (Chandler et al. 2017; Adler et al. 2020). When coupled with

Erin Roger

erin.roger@csiro.au

1 CSIRO Atlas of Living Australia, Sydney, NSW, Australia

2 School of Chemistry, University of Sydney, Sydney, NSW, Australia

3 Citizen Science Node, Charles Perkins Centre, University of Sydney, Sydney, NSW, Australia its potential to engage communities meaningfully in science, this potential to increase both the temporal and spatial scale of science, uniquely positions citizen science to affect genuine scientific, social and environmental outcomes (Bonney et al. 2014). The value citizen scientists receive from participating is manifold and varied, often providing a sense of community, a mechanism to contribute and increased scientific literacy, social interaction, and purpose (West and Pateman 2015). Recently there has been considerable debate about the use of the term and definition of citizen science (Cooper et al. 2021). For this paper, we consider citizen science to be an enabler of anyone without formal scientific credentials to engage in authoritative knowledge production.

With a large and diverse pool of potential participants available in cities, urban ecosystems and urban species have great capacity for the focus of citizen science projects (Adler et al. 2020). Urban-centred citizen science projects can provide data from areas not typically accessible to professional scientists such as backyards and school grounds (Saunders et al. 2018; Gracanin et al. 2020). Furthermore, they have the potential to collect observation rich, continuous data sets -which are rare even in professional settings- thereby providing a detailed window into urban ecology (Callaghan et al. 
2018 , 2019). Urban projects can also help address fascinating scientific questions with a range of projects and methodologies employing citizen scientists to better understand various aspects of ecology in cities (Saunders et al. 2018; Callaghan et al. 2019; Gracanin et al. 2020). Finally, given the socially and culturally diverse nature of cities (Forrest and Dunn 2011), urban based projects have the potential to attract a wide range of participants (cultures, backgrounds, ages and mobilities). Given the increasing recognition that the quality of science can be significantly enhanced by increasing the diversity of people involved in science (Nielsen et al. 2018; Swartz et al. 2019), urban based citizen science projects should be considered good for science (Brouwer and Hessels 2019).

Citizen science can serve as an important reminder that urban living does not preclude opportunities to observe, learn and contribute to our understanding of the natural world; it just means we sometimes need to look a little closer (Zellmer et al. 2020). Urban landscapes are largely perceived to be dominated by introduced species and less complex in species composition (Threlfall and Kendall 2018). However, species richness has been observed to actually increase for some species as is the case of urban grasslands (Soanes et al. 2018). In addition, the capacity for species to persist in urban environments or indeed for urban environments to serve as a last chance refuge, has been well described (Soanes et al. 2018; Soanes and Lentini 2019). Therefore, finding pockets of wild spaces in urban settings or recording observations at microscales can often result in surprising local-scale diversity (Soanes et al. 2018). With its highly urban population, growing cities, and unique flora and fauna, the importance of learning more about Australia's urban biodiversity and its role in conservation is critical (Threlfall and Kendall 2018; Soanes and Lentini 2019).

Australia's population predominantly lives in cities with over $70 \%$ of 23.4 million people now living in a major city (72\% major cities and $10 \%$ outer or regional area) (Australian Census Data 2019). This percentage is set to grow, with the number of Australians living in major cities increasing annually (Australian Census Data 2019), reflecting a growing global trend of increased urbanisation. Due to urbanisation and lifestyles built largely around inside recreation (e.g. gyms and television), urban dwellers are increasingly disconnected from nature (Kesebir and Kesebir 2017). Citizen science urban ecology projects are one mechanism to reconnect people of all ages with nature, by focusing attention on the natural phenomena within local environments. A broad range of projects could provide opportunities to involve communities in science by monitoring and reporting what is often, quite literally in their own backyard.

Below, we provide an overview of Australian urban citizen science projects. Our aims are to showcase examples of existing projects and provide recommendations for how to further increase their scale, fill critical information gaps and increase participation and retention in projects. We hope this will pave the way for further initiatives by demonstrating that citizen science is a tool that can be used not only to improve management outcomes but also to grow the public's appreciation of nature in cities, by increasing awareness that nature is not just confined to wild spaces.

\section{Urban citizen science projects in Australia}

To explore the breadth of urban focused ecology citizen science projects in Australia, we undertook an analysis from August through to November of 2020 of existing Australian citizen science projects using the Australian Citizen Science Association's (ACSA) Citizen Science Project Finder (2020), which is hosted by the Atlas of Living Australia (ALA). The ALA is a digital, open infrastructure that pulls together Australian biodiversity data from multiple sources, making it accessible and reusable (Belbin et al. 2021). ACSA is a member-based association that seeks to advance citizen science through the sharing of knowledge, collaboration, capacity building and advocacy. The ACSA Project Finder was designed as a resource to discover and connect with citizen science projects in Australia, by helping members of the citizen science community learn about each other's projects and provide opportunities to volunteer or get involved. To undertake our analysis, we refined our search terms to 'active' and 'ecology' projects which focused on urban areas. Our analysis excludes ad hoc citizen science (which is not tied to a project and therefore not included in the Project Finder) that can be undertaken using one of the many applications for collecting data e.g. iNaturalist, eBird. We excluded them as they are not discreet projects but rather a means to collect data at any time and in any environment. Their exclusion from our analysis does not mean that we do not perceive value in this approach and recognise that ad hoc observations are providing valuable data (Mesaglio and Callaghan 2021). We also acknowledge there are additional citizen science projects not listed in the Project Finder, such as school-based projects or those with fixed participants. Still, our approach provides a snapshot of the range of urban focused citizen science projects in Australia on which to base our recommendations.

Despite the benefits of urban based citizen science ecology projects, only 19 (or 5.3\%) out of a total of 458 active citizen science projects (192 active and ecology projects) listed in the ACSAs Project Finder (Table 1) had a specific focus on urban environments. Given the number of people living in urban environments in Australia, this constitutes a significant underrepresentation of projects tailored for urban dwellers. Furthermore, most of the 19 projects focused on four major cities in Australia (Sydney, Brisbane, Perth and Adelaide) with notable omissions of other capitals 


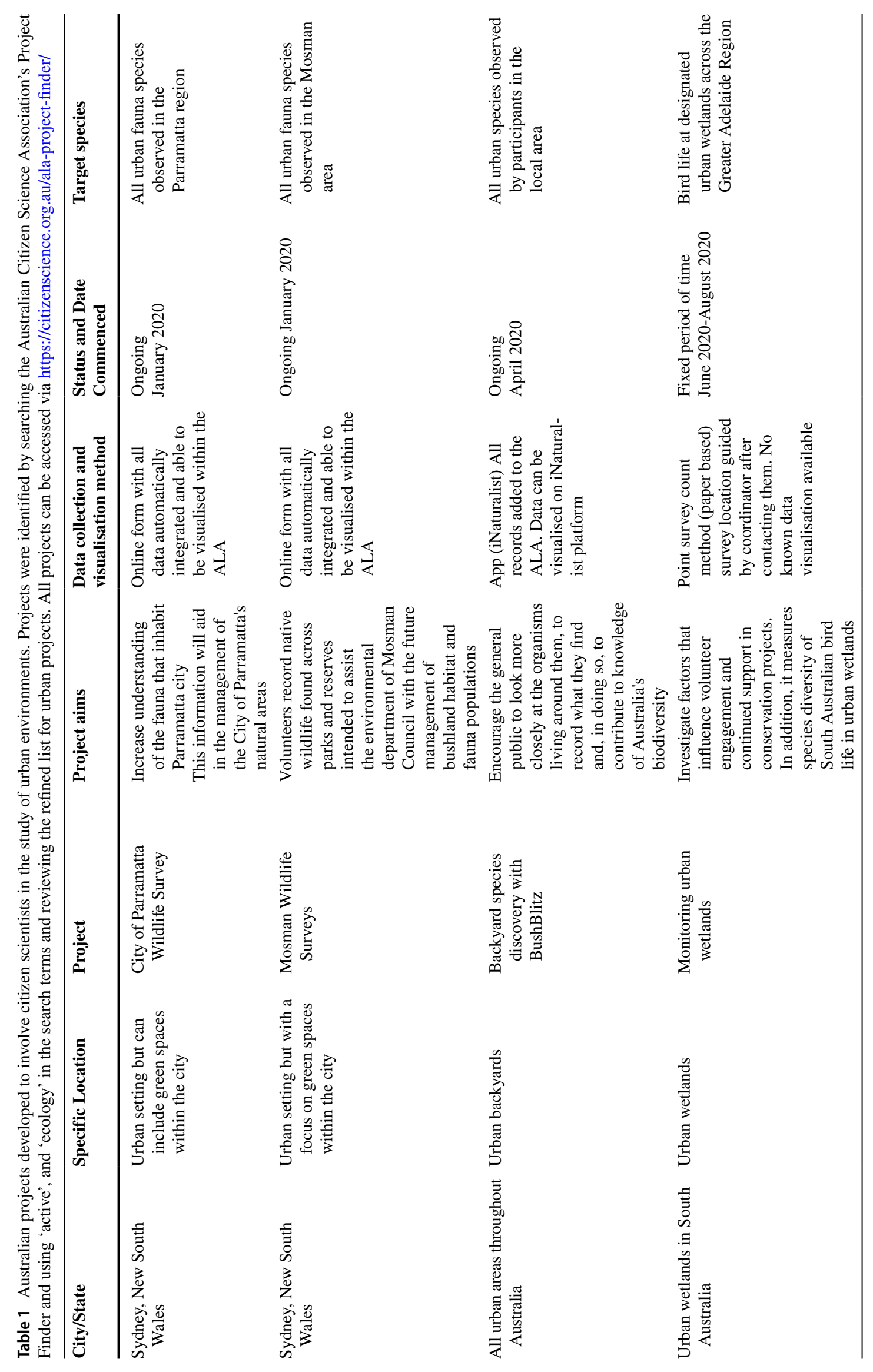




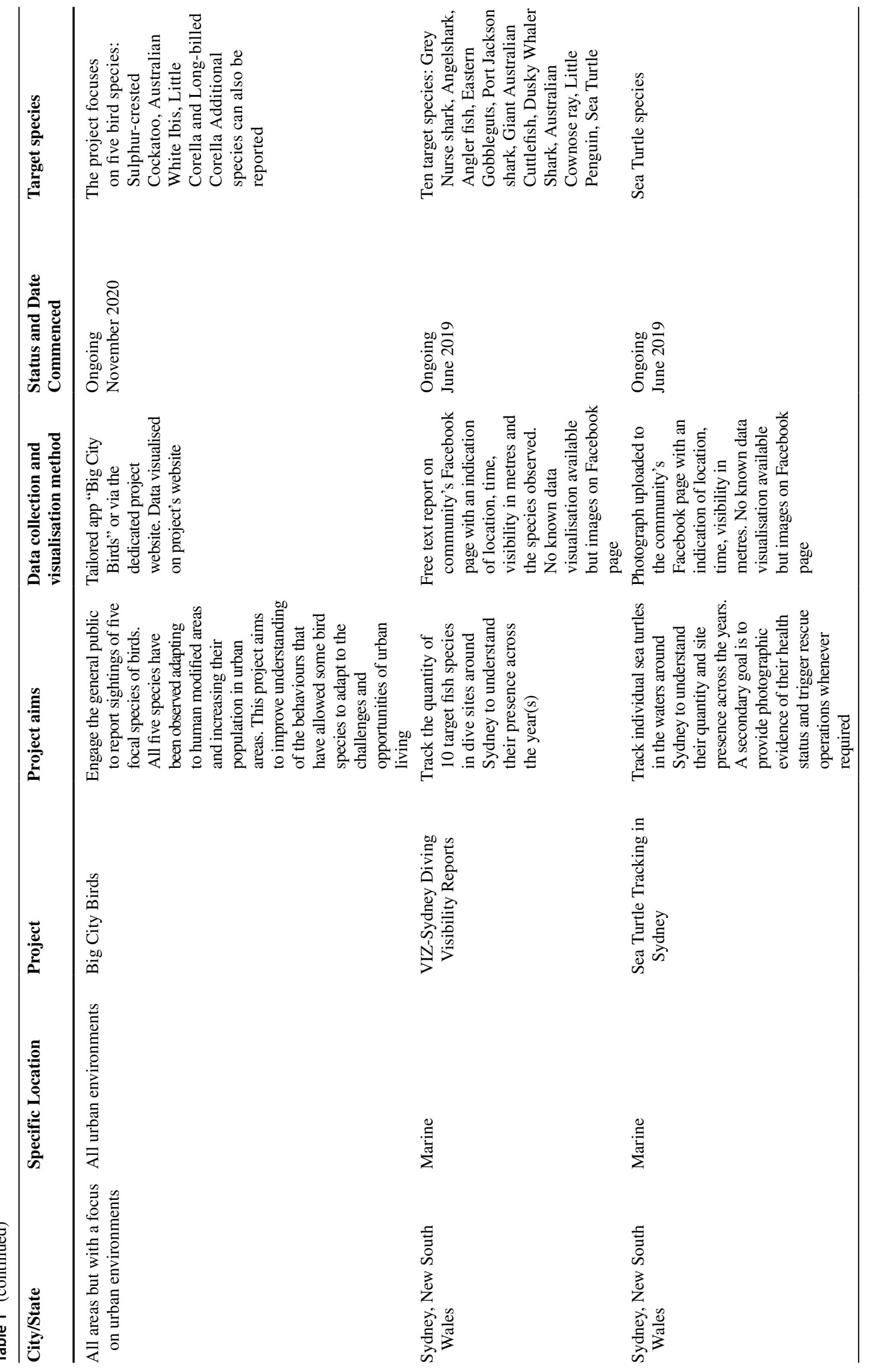




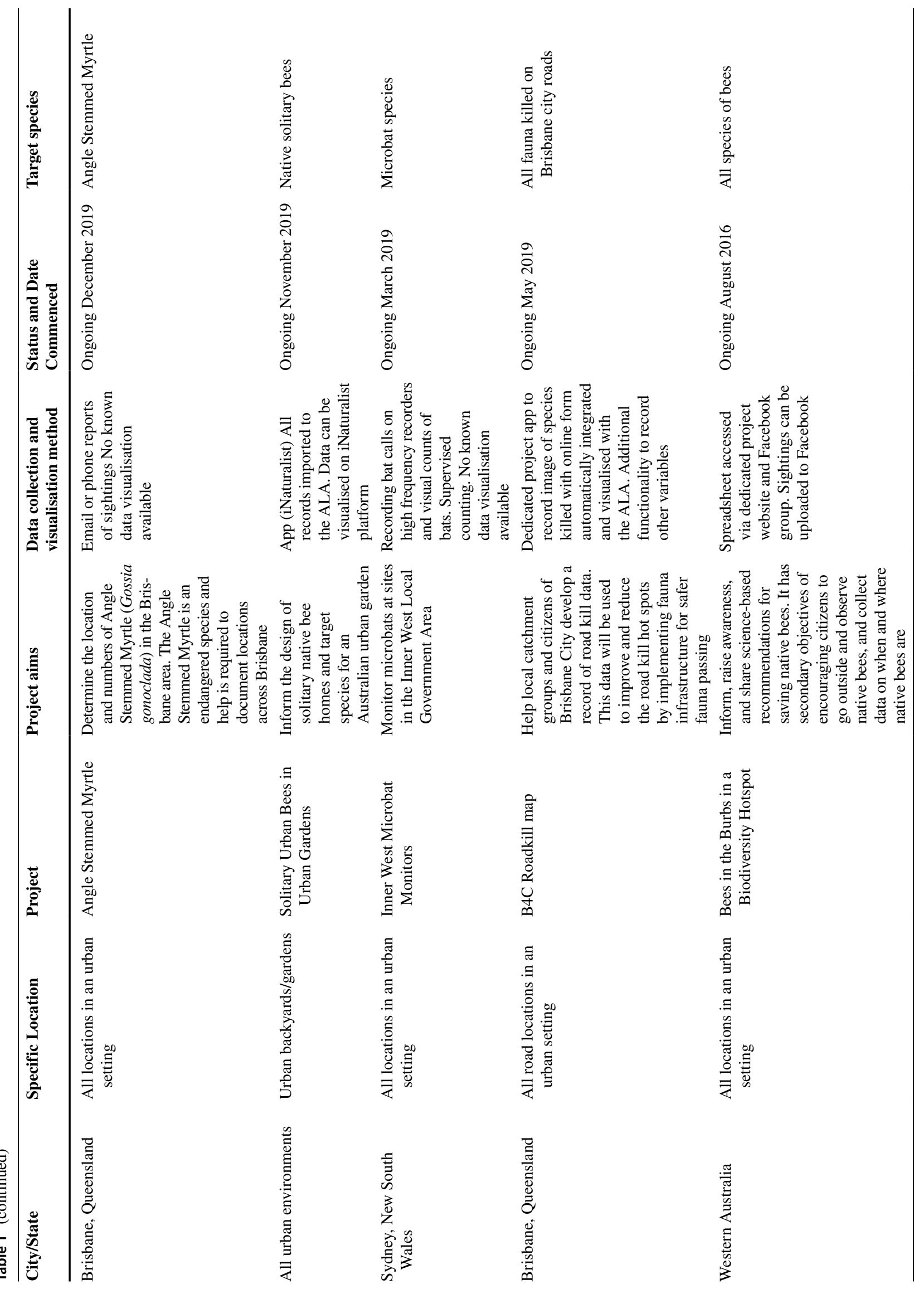




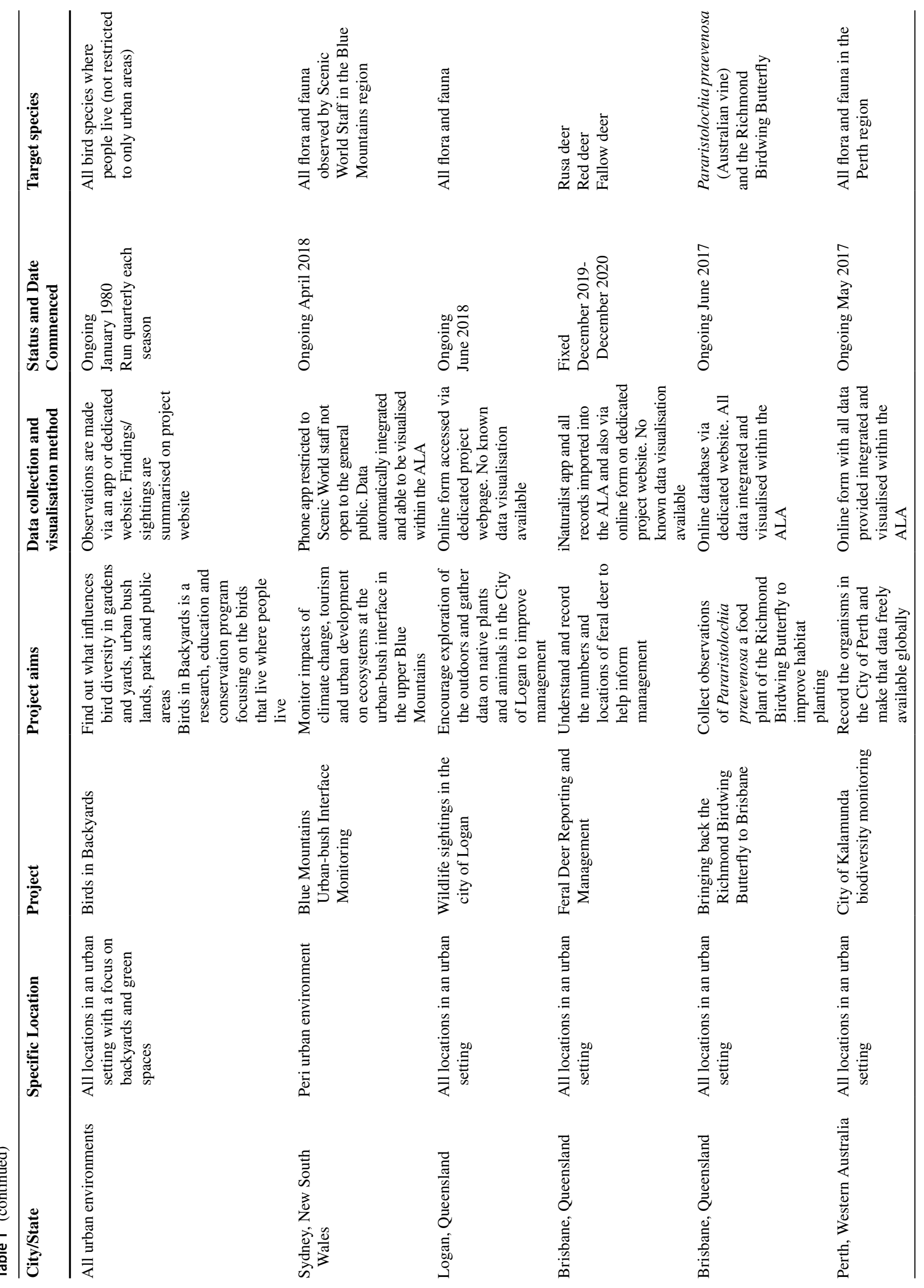




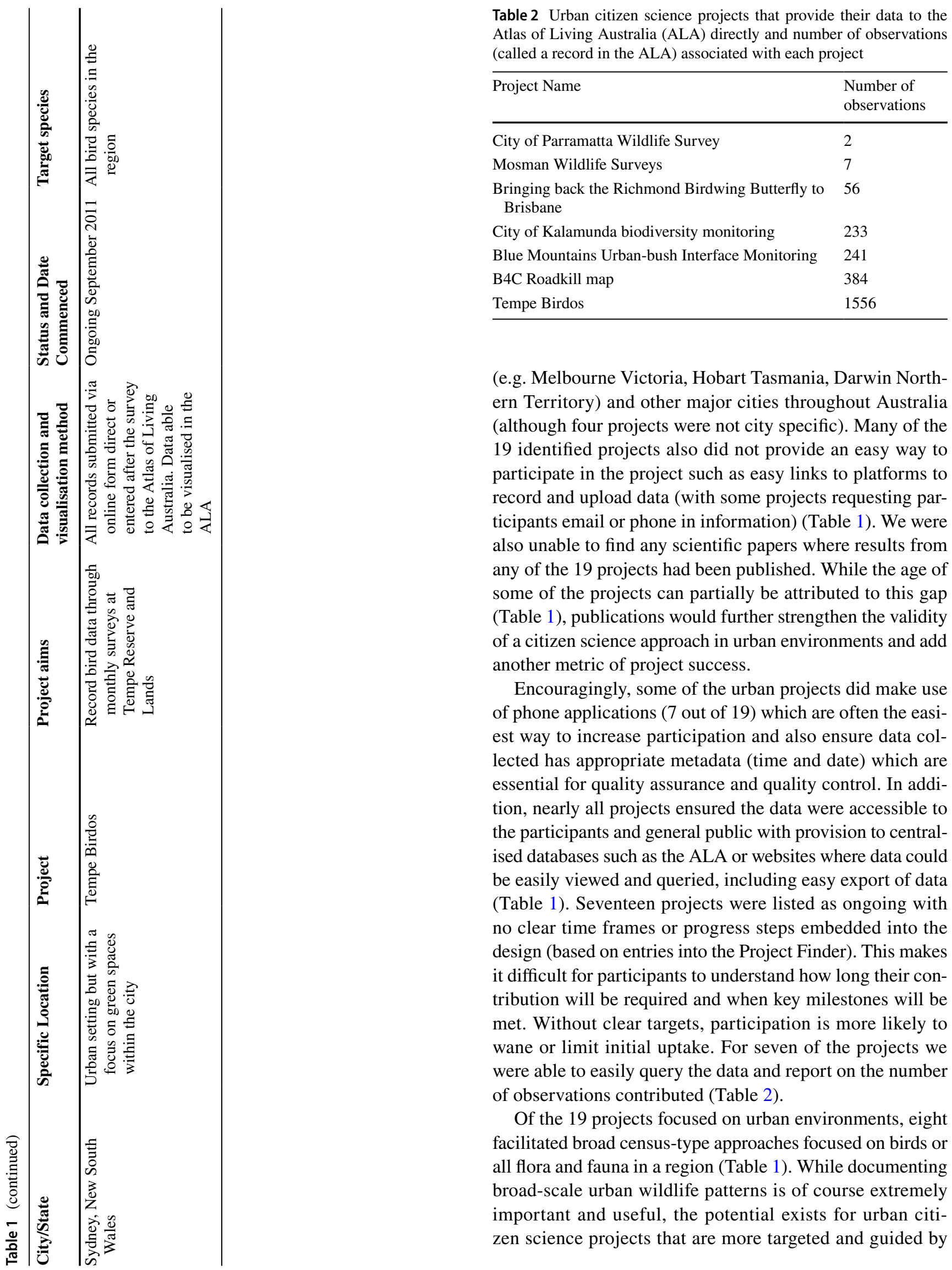

Table 2 Urban citizen science projects that provide their data to the Alas of Living Australia (ALA) directly and number of observations

\begin{tabular}{ll}
\hline City of Parramatta Wildlife Survey & 2 \\
Mosman Wildlife Surveys & 7 \\
Bringing back the Richmond Birdwing Butterfly to & 56 \\
Brisbane & \\
City of Kalamunda biodiversity monitoring & 233 \\
Blue Mountains Urban-bush Interface Monitoring & 241 \\
B4C Roadkill map & 384 \\
Tempe Birdos & 1556 \\
\hline
\end{tabular}

(e.g. Melbourne Victoria, Hobart Tasmania, Darwin Northern Territory) and other major cities throughout Australia Many of the asy way to to ord and upload data (with s pants email or phone in informati so unable to find any scientific pap ny of the 19 projects had been some of the projects can partially be attributed to this gap (Table 1), publications would further strengthen the validity of a citizen science approach in urban environments and add ther metric of project success.

Encouragingly, some of the urban projects did make use of phone applications ( 7 out of 19) which are often the easiest way to increase participation and also ensure data collected has appropriate metadata (time and date) which are essential for quality assurance and quality control. In addiion, nearly all projects ensured the data were accessible to he participants and general public with provision to centralised databases such as the ALA or websites where data could be easily viewed and queried, including easy export of data (Table 1). Seventeen projects were listed as ongoing with no clear time frames or progress steps embedded into the design (based on entries into the Project Finder). This makes it difficult for participants to understand how long their conribution will be required and when key milestones will be met. Without clear targets, participation is more likely to wane or limit initial uptake. For seven of the projects we were able to easily query the data and report on the number observations contributed (Table 2)

Of the 19 projects focused on urban environments, eight facilitated broad census-type approaches focused on birds or all flora and fauna in a region (Table 1). While documenting broad-scale urban wildlife patterns is of course extremely important and useful, the potential exists for urban citizen science projects that are more targeted and guided by 
narrower research questions. For example, van der Ree et al. (2006) found that some species are adapting to urban environments and thriving or re-colonising areas they were once extirpated from, often in response to increased availability of resources and habitat. As cities continue to grow and expand, exploration of which species are able to persist and recolonise in urban and peri-urban environments and which have been pushed out is incredibly valuable. Additionally, projects seeking to understand what morphological, biological or ecological species traits lend themselves to urban environments would be incredibly important for policy-makers and urban planners. For example, in our analysis only Big City Birds (Fig. 1) had an explicit aim of understanding species adaptations to living in urban environments.

Regarding more narrowly targeted research, citizen science projects could be potentially valuable for documenting threatened species' distribution and persistence in urban environments. Recent literature has documented the importance of cities as refuges for threatened species (Soanes and Lentini 2019). Ives et al. (2015) found that $30 \%$ of Australia's threatened species occur in cities and that a small subset of these are actually highly restricted to cities, especially for flora, such as the fringed spider orchid (Caladenia thysanochila) whose distribution is found entirely within a region of Melbourne. Additional research is required to identify and develop focused recovery planning and active management and improvement of urban habitat (van der Ree et al. 2006; Ives et al. 2015; Soanes et al. 2018). However, despite the potential for citizen science projects to contribute to this goal, only two of the 19 projects found focused on a threatened species: The Bring Back the Richmond Birdwing Butterfly project and the Angle Stemmed Myrtle projects (both based in Brisbane). Increasing the number of such projects focus on threatened species in cities could generate the information needed to help shape urban conservation actions and urban design.

Indeed, increasing the awareness of the importance of cities for the protection of populations in a variety of urban habitats remains an ongoing challenge (Soanes et al. 2018; Soanes and Lentini 2019). Many spaces in urban environments such as riparian corridors, road verges and disused railway lines can play an important role in connecting habitat patches across urban areas (Soanes et al. 2018). For example, trees along median strips can facilitate gene flow and connectivity among populations (Threlfall and Kendal 2018). Our search of the Project Finder did not find any citizen science projects with the aim of understanding abundance and patterns of persistence over time in different types of habitat in the urban environment. Citizen science projects that focus on this information could help to generate information needed by planners and raise the profile of urban areas for achieving conservation outcomes (Callaghan et al. 2018).

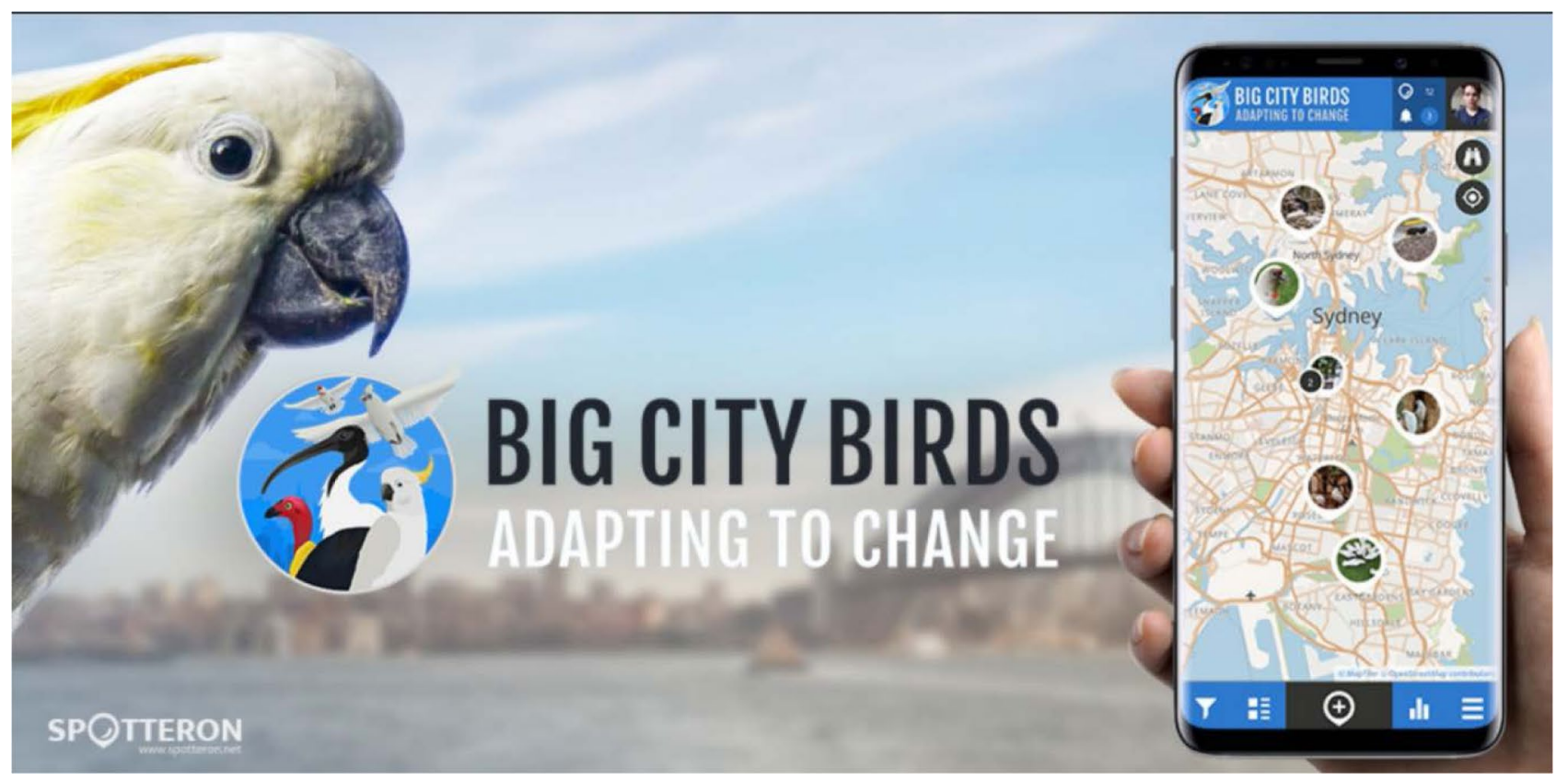

Fig. 1 The Big City Birds citizen science project focuses on the behaviour of five species of birds that allowed them to adapt to the challenges and opportunities of urban living. Image by Spotteron, supplied by John Martin, and used with permission 


\section{Recommendations for urban-ecology citizen science initiatives}

Further considerations and efforts are needed to grow participation and maintain momentum in citizen science. Based on our findings and personal experiences, we have developed the following recommendations for those considering designing and developing new citizen science projects in cities.

1. Increase the number of urban based citizen science projects thereby tapping into a large pool of potential participants and addressing gaps in existing citizen science approaches.

2. Give serious consideration to the accessibility of projects to ensure projects are easy to contribute to and join (e.g., via apps and websites) and minimising complicated mechanisms of participation (such a requiring calling to report data). Clear pathways for involvement can be achieved by designing or utilising accessible tools or project infrastructure and data collection methods. This is all the more important given the culturally and linguistically diverse nature of cities.

3. Articulate a common purpose focused on urban ecology and provide clear time commitments and milestones to increase uptake and provide time-poor participants with an understanding of the requirements and goals from the outset.

4. Develop targeted research questions which help address gaps in knowledge, such as projects that focus on adaptability and suitability of species to urban environments.

5. Design projects that improve awareness and understanding of threatened species distribution and persistence in urban environments and how to conserve them.

6. Ensure data are accessible and easy to visualise by nonscientists, and participants understand how they will or can be used to inform basic scientific and applied goals and how the project will be evaluated more broadly.

\section{Challenges of urban citizen science}

The challenges associated with citizen science have been widely documented (Bonney et al. 2014; Chandler et al. 2017; Ceccaroni et al. 2019; Adler et al. 2020; Roger et al. 2020), and it is not our intent to fully detail them here. However, we do acknowledge that full realisation of citizen science's potential will take time and require iterative research and invigorated practice to address the authenticity, validity and ethical use of citizen science data for scientific research. To do so, additional investment in support infrastructure and tools, standards and training are required. While issues with data quality and interoperability have been given the most prominence in the literature (Bonney et al. 2014; Chandler et al. 2017), recent studies have documented that accuracy can be comparable to expert-collected data provided that the proper training and tools are used (Aceves-Bueno et al. 2017; Mesaglio and Callaghan 2021). While we acknowledge a citizen science approach is not always appropriate (e.g. safety, technical requirements, sensitive data), the citizen science and research communities need to elevate discussions of and advocacy for citizen science, and demonstrate that, when properly resourced, citizen science can deliver comparable data and results with the potential to inform policy (Mesaglio and Callaghan 2021). This is especially true for urban environments where the majority of the world's people now reside.

An important but complex challenge for the citizen science community to address are more formalised human and animal ethical considerations in project design and implementation. For example, open sharing of sensitive species and culturally significant data has been raised as a concern (Roger et al. 2020). To some extent this is being overcome by the adoption of website features such as species filters (whereby locations for species of concern cannot be identified by the public) or low-resolution spatial data being provided instead of an exact location. There are additional efforts underway globally to address these issues more fully. But animal ethics and the necessary approvals in a citizen science context remain an emerging issue that ethics committees have not routinely considered in the past. Recently the journal 'Citizen Science Theory and Practice' released a dedicated issue on human ethics (Rasmussen and Cooper 2019) and the issues are extensive and beyond the scope of this article to address in full. However, properly addressing human ethics will be particularly challenging given citizen science largely operates at an extra institutional basis (Rasmussen and Cooper 2019). Outstanding issues that require further consideration include equitable access to published studies that use citizen science, lack of oversight and recourse measures, proper attribution, attracting greater diversity and issues of exploitation and payment. It will be an ongoing challenge to ensure these issues are adequately considered but at the same time do not hinder or limit citizen science through structures and processes that are largely inaccessible to the public.

Running citizen science projects designed for urban dwellers also requires perhaps more focused attention in certain contexts and areas in design, implementation, and communication. To attract the wide diversity of participants a city has to offer, urban citizen science projects need to be more mindful of language, social and cultural barriers when communicating about the project. Genuinely making sure projects are more open and accessible can add extra costs and 
complexities to designing projects such as producing materials in multiple languages and accessible formats. Project coordinators may also need additional training to work effectively with a wide range of communities to properly address their concerns and tap into their local knowledge. Perhaps the greatest barrier to increasing the number of urban ecology citizen science projects is convincing urban dwellers of the benefits of citizen science in urban areas and that they can make important contributions. One example of a global initiative that is trying to change this narrative is the Great City Nature Challenge (https://citynaturechallenge.org/). The Great City Nature Challenge has been running since 2016 and is founded on a competition among cities, with participating cities encouraging urban observers to gather the most observations about nature over a given time. Projects such as this can greatly increase urban dwellers understanding of biodiversity; however, what is also needed is interpretation and use of the observations for decision-making (reported back to participants) to demonstrate genuine impact and maintain enthusiasm.

\section{Conclusions}

Cities are an extreme example of how humans modify their environments (Adler et al. 2020). Professional scientists alone cannot achieve the scale and resolutions needed to fully understand and monitor how urbanisation affects global and local biodiversity. Due to its potential to engage tens of thousands if not millions of individuals, citizen science may represent a more sensitive tool for measuring ecological changes in cities, compared to the more detailed but less frequent and spatially isolated monitoring common to traditional scientific research. Citizen science could also help shift the overriding narrative that cities are dominated by introduced species and are less complex in species composition. This shift may in turn afford greater concentrated effort towards conserving remaining urban green spaces. By involving members of the public in scientific research, citizen science can help researchers and policymakers understand global problems and support local solutions (Roger et al. 2019). For example, Tulloch et al. (2020) highlighted the role citizen science has in monitoring the increased use of urban and peri-urban habitats of bird species after Australia's horrific 2019-20 bushfire season. They noted that citizen scientists are helping document species moving into and using urban habitat as refuges after their habitats burned. Given Australia's population distribution, emerging questions such as the extent of cities as refuges represents an opportunity to trial novel citizen science approaches that could attract a greater diversity of participants from densely populated towns and cities.
Changes in urban environments require close and careful monitoring, and participation in citizen science has the potential to grow public appreciation and understanding of nature and an awareness that it is not confined to wild spaces. In doing so, citizen science can be a quantitative lens to observe our urban environments that can lead to increased understanding of them and how they change, (Callaghan et al. 2019; Mesaglio and Callaghan 2021) and provide an opportunity for urban residents to reconnect with nature (Ives et al. 2018). Such connections can be enabled by networks such as the Clean Air and Urban Landscape Hub (CAUL) in Australia (https://nespurban.edu.au/) and the Urban Wildlife Information Network (UWIN) in North America (https://urbanwildlifeinfo.org/). As global cities continue to expand both in size and human population density, understanding their ecology and the interplay between humans and the natural environment will become all the more crucial. Although our analysis was focused on Australia, we feel the recommendations stemming from it have broader application. However, our primary finding of underrepresentation of urban settings within citizen science projects should be examined in other countries. Despite the challenges, citizen science is one mechanism to better understand our relationship with urban environments. We urge citizen science practitioners to adopt our recommendations thereby enabling residents to engage in their surroundings, share their knowledge and views, generate new knowledge, and, ultimately, play a part in informing the management of biodiversity and greenspaces in their local urban environments.

Acknowledgements We acknowledge and pay respect to the Gadigal people of the Eora Nation, the traditional owners of the land on which we research, teach, work and collaborate at both the University of Sydney and CSIRO. We also acknowledge the feedback from two anonymous reviewers and the editor whose input significantly improved the paper.

Authors' contributions ER \& AM conceptualised the manuscript; ER took the lead in writing with contribution from AM.

Funding N/A.

Data availability N/A.

Code availability N/A.

\section{Declarations}

\section{Ethics approval N/A}

Consent to participate N/A

Consent for publication Yes. We confirm that this work is original and has not been published elsewhere, nor is it currently under consideration for publication elsewhere. 
Conflicts of interest Erin Roger is the former Chair of the Australian Citizen Science Association and employed by the Atlas of Living Australia (based in CSIRO Sydney). Alice Motion is the Host Representative of the Australian Citizen Science Association as a member of the School of Chemistry at the University of Sydney. She is co-chair of the Citizen Science Node at the University of Sydney.

Open Access This article is licensed under a Creative Commons Attribution 4.0 International License, which permits use, sharing, adaptation, distribution and reproduction in any medium or format, as long as you give appropriate credit to the original author(s) and the source, provide a link to the Creative Commons licence, and indicate if changes were made. The images or other third party material in this article are included in the article's Creative Commons licence, unless indicated otherwise in a credit line to the material. If material is not included in the article's Creative Commons licence and your intended use is not permitted by statutory regulation or exceeds the permitted use, you will need to obtain permission directly from the copyright holder. To view a copy of this licence, visit http://creativecommons.org/licenses/by/4.0/.

\section{References}

Aceves-Bueno E, Adeleye AS, Feraud M, Huang Y, Tao M, Yang Y, Anderson SE (2017) The accuracy of citizen science data: a quantitative review. Bull Ecol Soc Am 98:278-290. https://doi.org/10. 1002/bes2.1336

Adler FR, Green AM, Şekercioğlu CH (2020) Citizen science in ecology: a place for humans in nature. Ann NY Acad Sci 1469:52-64. https://doi.org/10.1111/nyas.14340

Australian Bureau of Statistics (2019) Regional population growth, Australia, 2017-18. ABS cat no. 3218.0. Canberra https://www. abs.gov.au/statistics/people/population/regional-population/201819 Accessed 11 November 2020

Australian Citizen Science Project Finder (2020) https://biocollect.ala. org.au/acsa Accessed 12 November 2020

Belbin L, Wallis E, Hobern D, Zerger Z (2021) The Atlas of Living Australia: History, current state and future directions. Biodivers Data J 9:e65023. https://doi.org/10.3897/BDJ.9.e65023

Bonney R, Shirk JL, Phillips TB, Wiggins A, Ballard HL, MillerRushing AJ, Parrish JK (2014) Citizen science. Next Steps for Citizen Science Science 343:1436-1437. https://doi.org/10.1126/ science. 1251554

Brouwer S, Hessels LK (2019) Increasing research impact with citizen science: The influence of recruitment strategies on sample diversity. Public Underst Sci 28(5):606-621. https://doi.org/10.1177/ 0963662519840934

Callaghan CT, Major RE, Lyons MB, Martin JM, Kingsford RT (2018) The effects of local and landscape habitat attributes on bird diversity in urban greenspaces. Ecosphere 9(7):e02347. https://doi.org/ $10.1002 /$ ecs 2.2347

Callaghan CT, Major RE, Lyons MB, Martin JM, Wilshire JH, Kingsford RT, Cornwell WK (2019) Using citizen science data to define and track restoration targets in urban areas. J Appl Ecol 56(8):19982006. https://doi.org/10.1111/1365-2664.13421

Ceccaroni L, Bibby J, Roger E, Flemons P, Michael K, Fagan L, Oliver JL (2019) Opportunities and Risks for Citizen Science in the Age of Artificial Intelligence. Citiz Sci Theory Pr 4(1):29. https://doi. org/10.5334/cstp. 241

Chandler M, See L, Copas K, Bonde AM, Lo'pez B C, Danielsen F, Legind JK, Masinde S, Miller-Rushing J, Newman G, Rosemartin A, Turak E, (2017) Contribution of citizen science towards international biodiversity monitoring. Biol Conserv 213:280-294. https:// doi.org/10.1016/j.biocon.2016.09.004
Cooper C, Hawn CL, Larson LR, Parrish JK, Bowser G, Cavalier D, Dunn RR, Haklay M, Gupta KK, Jelks NO, Johnson VA, Katti M, Leggett Z, Wilson OR, Wilson S (2021) Inclusion in citizen science: the conundrum of rebranding. Science 372:1386-1388. https://doi.org/10.1126/science.abi6487

Forrest J, Dunn K (2011) Attitudes to Diversity: new perspectives on the ethnic geography of Brisbane. Australia Aust Geogr 42(4):435-453. https://doi.org/10.1080/00049182.2012.619957

Gracanin A, Roger E, Katsis AC, O'Loughlin LS, Emery NJ, O'Cock JF, O'Hanlon JC (2020) An artificial bird nest experiment in urban environments: Lessons from a school-based citizen science program. Austral Ecol 45(5):523-528. https://doi.org/10.1111/aec. 12859

Ives CD, Lentini PE, Threlfall CG, Ikin K, Shanahan DF, Garrard GE, Bekessy SA, Fuller L, Mumaw L, Rayner L, Rowe R, Valentine LE, Kendal D (2015) Cities Are Hotspots for Threatened Species Glob Ecol Biogeogr 25:117-126. https://doi.org/10.1111/ geb. 12404

Ives CD, Abson DJ, von Wehrden H, Dorninger C, Klaniecki K, Fischer J (2018) Reconnecting with nature for sustainability. Sustain Sci 13:1389-1397. https://doi.org/10.1007/s11625-018-0542-9

Kesebir S, Kesebir P (2017) A Growing Disconnection From Nature Is Evident in Cultural Products. Perspect Psychol Sci 12:258-259. https://doi.org/10.1177/1745691616662473

Mesaglio T, Callaghan CT (2021) An overview of the history, current contributions and future outlook of iNaturalist in Australia. Wildlife Res. https://doi.org/10.1071/WR20154

Nielsen MW, Block CW, Schiebinger L (2018) Making gender diversity work for scientific discovery and innovation. Nat Hum Behav 2:726-734. https://doi.org/10.1038/s41562-018-0433-1

Rasmussen LM, Cooper C (2019) Citiz Sci Theory Pr 4(1):5. https:// doi.org/10.5334/cstp.235

Roger E, Turak E, Tegart P (2019) Adopting Citizen Science as a Tool to Enhance Monitoring for an Environment Agency. CSTP 4(1):1-9. https://doi.org/10.5334/cstp.231

Roger E, Tegart P, Dowsett R, Kinsela MA, Harley MD, Ortac G (2020) Maximising the potential for citizen science in New South Wales. Aust J Zool 40:449-461. https://doi.org/10.7882/AZ.2019. 023

Saunders M, Roger E, Geary WL et al (2018) Citizen science in schools: Engaging students in research on urban habitat for pollinators. Austral Ecol 43:635-642. https://doi.org/10.1111/aec. 12608

Soanes K, Sievers M, Chee YE, Williams NSG, Bhardwaj M, Marshall AJ, Parris KM (2018) Correcting common misconceptions to inspire conservation action in urban environments. Conserv Biol 33(20):300-306. https://doi.org/10.1111/cobi.13193

Soanes K, Lentini PE (2019) When cities are the last chance for saving cities. Front Ecol Environ 17(4):225-231. https://doi.org/10. 1002/fee.2032

Swartz TH, Palermo AS, Masur SK, Aberg JA (2019) The Science and Value of Diversity: Closing the Gaps in Our Understanding of Inclusion and Diversity. J Infect Dis 220(2):S33-S41. https:// doi.org/10.1093/infdis/jiz174

Threlfall CG, Kendal D (2018) The distinct ecological and social roles that wild spaces play in urban ecosystems. Urban for Urban Gree 29:328-356. https://doi.org/10.1016/j.ufug.2017.05.012

Tulloch A, Reside A, Garrard G, Ward M, Awasty M (2020) Birdwatching increased tenfold last lockdown. Don't stop, it's a huge help for bushfire recovery. The Conversation. Accessed 29 August 2020. https://theconversation.com/birdwatching-increased-tenfold-lastlockdown-dont-stop-its-a-huge-help-for-bushfire-recovery-141970

van der Ree R, Mcdonnell MJ, Temby I, Nelson J, Whittingham E (2006) The establishment and dynamics of a recently established urban camp of flying foxes (Pteropus poliocephalus) outside their 
geographic range. J Zool 268:177-185. https://doi.org/10.1111/j. 1469-7998.2005.00005.x

West S, Pateman R (2016) Recruiting and retaining participants in citizen science: What can be learnt from the volunteering literature? CSTP 1(2):15.1-10. https://doi.org/10.5334/cstp.8
Zellmer AJ, Wood EM, Surasinghe T, Putman BJ, Pauly GB, Magle SB, Lewis JS, Kay CAM, Fidino M (2020) What can we learn from wildlife sightings during the COVID-19 global shutdown? Ecosphere 11(8):e03215. https://doi.org/10.1002/ecs2.3215 